\title{
The Application and Research of Information Technology of Cloud Computing in Colleges and Universities
}

\author{
Ying Luo ${ }^{1, \text { a }}$, Miaomiao $\mathrm{Li}^{2, \mathrm{~b}}$ \\ ${ }^{1}$ TVET Research Institute, Jiangxi Science \& Technology Normal University; Nanchang 330038, \\ China; \\ ${ }^{2}$ Education School, Jiangxi Science \&Technology Normal University, Nanchang 330038, China. \\ amooonly@126.com; 'biMiaomiao0710@163.com
}

Keywords: cloud computing; university information system; application

\begin{abstract}
As an emerging technology, cloud computing has a profound impact on Internet. This paper introduces the concept and characteristics of cloud computing, then studies the current status of university information technology, and analyzes how cloud computing promote the development of university information technology. Cloud computing will efficiently use existing hardware resources, change the using mode of teaching soft, enhance the sharing of information resources and teaching resources.
\end{abstract}

\section{Introduction}

The development of computer technology and the appearance of computer network provide great convenience for daily information sharing and communication. At present, computer network architecture model is independent data computation, storage center and various service based on information transmission. On the basis of the development and application of network technology, multi-core processor and distributed storage technology, a new network framework model-cloud computing is put forwarded. It develops in the mode of information processing and application service architecture in network era and will be the development mainstream of future network. The emergence of cloud computing not only provides advantageous condition for the university informatization construction, but also promotes the development of our country's college career.

\section{The meaning and characteristics of cloud computing}

Cloud computing, a new computing model based on distributed system and grid computing development, is a new method of sharing infrastructure, facing large-scale distributed environment and cored by providing data storage and network service. It has the following characteristics.

Reliable and safe data storage. Cloud computing provides the most secure and reliable storage center. The data (such as document and media) will automatically synchronize and be used in all devices through Web, which avoid data loss or viruses due to storage in personal computer. At the same time, cloud computing supports data sharing through strict right management strategy.

Convenient and fast cloud service. In cloud computing era, users will not need to install and upgrade various application soft wares on the computer. Only having a web browser, can they use all kinds of service offered by cloud computing conveniently and fast, which will effectively reduce the difficulty curve of technology application and further promote the breadth and depth of Web service development.

Powerful computation ability. Cloud computing provides powerful computing capability for network application. It can provide 10 million per second computing ability for general users to complete various kinds of business requirement. But the super computing power is difficult to reach in general computing environment.

Economic benefit. It is predicted, compared with organization operation data center, storage cost of cloud computing service providers is only $1 / 10$, while the wide cost only $1 / 12$ and computing 
cost 1/3. This will help some institutions operate with relatively low construction cost.

\section{The existing problems in informatization construction in colleges and universities}

University informatization is to achieve all the courses informatization from the environment, resources to activities on the basis of network. The aim is to achieve the school teaching, scientific research, management, service activities and so on high efficiency and standardization, so as to improve the teaching quality, the level of scientific research and management objective.

In recent years, university informatization development model has become an important part of university development and construction. University information work has made great achievement both in the construction of infrastructure and personnel training, which has far-reaching significance to enhance the comprehensive strength of universities and reform the management system. But with the increasing development of information construction, the isomerism of the entire IT infrastructure heterogeneity, the limitation of traditional information technology, and other problems become more and more obvious.

Teaching equipment exist problems. For most ordinary colleges, infrastructure cannot keep up with the development level of informatization construction due to limited funds and aging equipment. However, in order to realize the informatization construction, the school must invest a lot of money while the high cost inputs bring great pressure to the institutes. Secondly, after the hardware facilities are equipped, the installation and maintenance of software also exists big problems. We should not only consider whether the current software resources can adapt to use now, but also need to consider the upgrading of software and the time requirement of applicable program, which make the informatization teaching can not be well reflected.

Teaching resources exist problems. To realize the construction of higher education informatization, the first problem is the uneven distribution of teaching resources. At present, the education system construction is often fragmented; network teaching platform is based on their own characteristics, the sharing and utilization degree of teaching resources is low, and databases lack information sharing mechanism and means.

The management organization exists problems. In the teaching, the management of hardware resources need specialized technical personnel to maintain. However, the school is generally equipped with management staff while related technical personnel are not balanced. Secondly, the various departments have different strategies to manage resources, resulting in unified resource management mode. It makes informatization construction integration lack unified and open technology standard. In the process of building resource platform, many difference exist in management, such as in storage format, data function module, system overall frame, etc.

\section{The application of cloud computing in university informatization}

The application of cloud computing technology reduces the hardware cost of informatization construction. For the universities, the informationization construction requires a lot of cost in hardware and network products, such as, server, setting the data center, etc. the investment is very huge, and along with the updating of products, colleges and universities need to constantly add new hardware facilities, so the hardware investment becomes a bottomless pit. The application of cloud computing in university can solve the problems well. The advantage of cloud computing liberates the restriction of hardware configuration to terminal, that is, even like mobile phone, mobile terminal and other low configuration equipment can also be use cloud computing. Therefore, the application of cloud computing in the university informatization construction can solve a lot of hardware investment cost, and don' t have to continuously update the hardware facilities, so as to use more money to build the cloud computing center and improve the informationzation level.

The application of cloud computing technology improves the reliability of university network server. The application of cloud computing technology effectively reduces the probability of error of the server and ensures the stable operation. In the network server of colleges and universities, once failure occurs, the campus network is likely to have no way to work, because most of data 
information is usually stored in the server of the campus network. Cloud computing model is constituted of millions of servers, even if one single server crashes, it does not affect the other servers and other servers can also find and restore the data rapidly to other servers, at the same time, the new server will replace the server to provide service, not affecting the use of data.

The application of cloud computing technology makes the resource sharing more wide. Colleges and universities establishing relationships can build information sharing space together through the cloud computing model and make everyone share infrastructure constituted of a large number of system, so as to improve the efficiency of resource sharing in colleges and universities. Each college participating in cooperation can acquire the needed information in real time through the cloud technology, which will make users' information need get great satisfaction. In cloud computing, the relevant data and resources in colleges and universities is not only stored in a computer, but in the (cloud) computer, to achieve resource sharing in greater range.

Cloud computer changes the use of the application software. In order to meet the needs of different students' learning needs, college computer room needs to install a number of application software, which will cause the burden of the computer. With the updating of computer software, the requirement of hardware is increasingly high, and the original computers face the elimination. Cloud computing can provide the function of online application software, the software application is similar to the loan, and the user only need to apply if want to use certain software.

\section{Summary}

Whether as a new technology or as a new business model, cloud computing announces it is possible to provide supercomputing service with low cost. Cloud computing not only reflects the characteristics of the current social network and has great potential in the process of education informatization, but also can provide the infrastructure and software environment for university teaching and research. Although the application of current cloud computing in university information construction still faces some challenges, the development trend of cloud computing has provided a new mode for the higher education informatization, and will inject new impetus for the new round of leap forward development of the whole college education.

\section{References}

[1] Mike Hogan. How Databases Can Meet the Demands of Cloud Computing [J].2008(2)

[2] Jim Baty. Take Your Business to a Higher Level: Sun Cloud Computing [J]. 2008(13)

[3]Rong Hua. On the application of cloud computing in colleges and universities [J]. Software, 2012, 33(7):139-140.

[4]Rong Hu. Study on application of cloud computing in the digital library[J]. Science and technology entrepreneurship monthly, 2011.

[5]Hongbo Li. Study on application of cloud computing in university digital campus[J]. Computer knowledge and technology, 2011.

[6]Qiuping Fu. Thinking on information construction in colleges and universities[J]. Journal of education information, 2009, (11): 11-12.

[7]Jinpeng Li, Cheng Cheng, Guoqiang Yang. The status and countermeasure analysis of university information construction[J]. Journal of optical disc technology, 2009, (7): 11-13. 